\title{
China on verge of putting man into space...
}

Beijing

China has launched its first unmanned spacecraft, Shenzhou, or "God Ship". The flight has made China the third country to launch a craft capable of carrying a person into space, and has been hailed as a milestone towards realizing that dream.

The vehicle was launched with the latest model of the Long March rocket, from the Jiuquan satellite-launching centre in the northwestern province of Gansu, at 6:30 a.m. local time on Saturday (20 November). The dome-shaped craft was in space for 21 hours and orbited the Earth 14 times before touching down in Inner Mongolia.

During the mission, experiments were conducted on remote sensing from space, environmental monitoring, space materials, life science, astronomy and physics. A new land- and sea-based monitoring and control network was put into use for the first time for the launch.

China's secret Manned Spaceflight Programme began in 1992. The first manned flight was originally planned to coincide with the fiftieth anniversary of the founding of the People's Republic of China in October - no reasons were given for the delay.

The spacecraft and the carrier rocket were developed mainly by the China Space Science and Technology Group. The Chinese Academy of Sciences and the Ministry of the Information Industry were also involved.

The official Xinhua News Agency said the launch would "strengthen the nation's comprehensive national strength, promote the development of science and technology, enhance national prestige and boost the nation's sense of pride and cohesiveness".

Officials say that a number of unmanned test flights are needed before an astronaut can be sent into space, but give no timetable. The Beijing-backed Hong Kong newspaper Wen Wei Po said a manned flight was "just around the corner", however.

Major Chinese newspapers did not appear until midday on Sunday, apparently waiting for the return of the spacecraft.
Reports about the launch covered the front pages of almost all major newspapers.

Russia is reported to have helped China with the development programme. The spacecraft weighed about 8.4 tonnes and was capable of accommodating up to four astronauts. It was said to be based on the Russian Soyuz, but with two pairs of solar panels to generate power, and a cylindrical forward module rather than a spherical one.

Moscow and Beijing signed an agreement to train Chinese cosmonauts in Russia after Russian president Boris Yeltsin visited China in 1996.

Two Chinese cosmonauts received training that year at the Star City Space Centre near Moscow in the full programme needed for a manned flight, as well as intensive courses in physics and Russian. The future astronauts are said to have been picked from among China's best fighter pilots.

China launched its first rocket in 1959. The country's first satellite, Dongfanghong, went into orbit in 1970.

\section{... as a new failed satellite launch embarrasses Japan}

\section{Tokyo}

Japan's space programme experienced a major setback last week when one of its H-II rockets had to be destroyed shortly after liftoff. An engine failure caused the launcher to deviate from its flight path.

The failure led to the resignation of Toshio Okazaki, vice-minister for the Science and Technology Agency (STA), who also took responsibility for the nuclear fuel accident at a uranium-reprocessing plant in Tokaimura in September. But his resignation fuelled criticism of the government for creating a scapegoat for mishaps at STA-related organizations.

The launcher carrying the Multifunctional Transport Satellite (MTSAT) was blown up seven minutes after its launch, on the instructions of the National Space Development Agency (NASDA). Agency officials say that the engine on the first stage of the launcher stopped working about four minutes after the launch, possibly because of a problem with the fuel pipe supplying hydrogen to the combustion chamber.

The failure, resulting in a total loss of $¥ 34.3$ billion (US $\$ 327$ million), was a blow to NASDA and its governing body, the STA, which had hoped to improve the space agency's reputation following last year's failure to launch the world's largest telecommunications satellite (see Nature 392, 321; 1998).

Three delays to the launch of the H-II rocket, initially planned for August, added insult to injury (see Nature 401, 204; 1999). NASDA admitted after the accident that it did not inspect the main engine thoroughly, because the same type of engine had worked in past missions.

Hirofumi Nakasone, director-general of STA, has promised a full investigation into the failure and a review of space development strategy under NASDA. "This does not mean that [Japan's] whole space development strategy has a problem, but the current system under NASDA clearly needs to be reviewed and made open to the public," said Nakasone.

Politicians from the ruling Liberal Democratic Party called for a drastic reorganization of the country's space programme after last year's launch failure. This view has strengthened after last week's incident, with a greater emphasis on reorganizing NASDA. This would include merging NASDA with the Institute of Space and Astronautical Science (ISAS) under the Ministry of Education, Science, Sports and Culture (Monbusho) after the planned merger of STA and Monbusho in 2001.

But space scientists are opposed to such a move, saying that a merger of NASDA, which is responsible for large-scale, mission-orientated programmes, and ISAS, an institute focusing on basic research, would be disastrous.

"The merger will not make the problems

ش๐ 1999 Macmillan Magazines Ltd

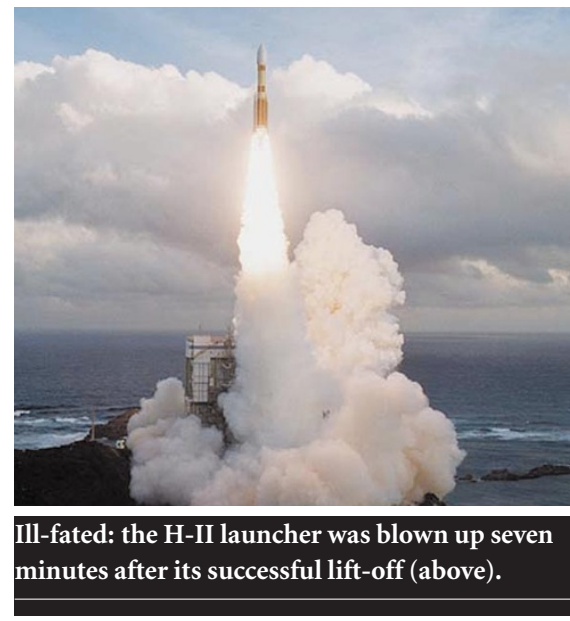

disappear," says Ryojiro Akiba, former director of ISAS and a member of STA's Space Activities Commission. "NASDA may have to shift from its current applicationorientated approach to a more technologyand research-based approach, and ISAS could provide support for such a move; but this should not be interpreted as a need to merge the two organizations."

The failure is also a serious blow to Japan's plan to join the satellite business. Rocket System, a commercial satellitelaunching company funded by 73 spacerelated companies, says the failure may affect its contract with two US companies to launch satellites using H-IIA rockets, which are based on H-II launchers. Asako Saegusa 